\title{
THE ROLE OF HEDONISM IN ETHICAL TOURISM
}

ABSTRACT: This paper investigates the role of emotion in the ethical choice processes of tourists. Specifically, it explores how hedonism is experienced and the links between hedonic experiences and intentions for future ethical behaviour. It adopts an interpretative phenomenological analysis (IPA) approach to examine the experience of emotion in self-defined ethical tourists' consumption of places. The findings highlight that emotionally charged experiences are powerful motivators of consumers' ethical choice. It identifies the role hedonism plays in rationalizing and reinforcing current and intended ethical behaviour. Finally, the paper discusses the importance of emotional experiences as a source of hedonic value in engaging individuals in consumption encounters.

Keywords: Ethical tourism, emotions, ethical consumption, interpretative phenomenological analysis, pleasure, enjoyment.

\section{INTRODUCTION}

Tourism is essentially a pleasure-seeking activity (Gnoth, 1997; Goossens, 2000). Such experiences are often thought of as highly intense, subjective, salient and intrinsically rewarding. Tourists tend to be deeply involved in the process of decision-making i.e. it involves a high order of conscious cognitive processing. Previous studies have pointed to the importance of understanding the emotive aspects of tourism experiences (e.g. Arnould \& Price, 1993; Celsi, Rose \& Leigh, 1993) and their impact on choice behaviour, recognising that tourism is often an emotionally charged consumer episode (e.g. Pearce, 2009). In relation to tourism destinations, Hosany \& Gilbert (2010) suggest that emotions have a significant role to play in influencing consumers' behavioural intentions. Other studies have employed emotion as the basis for segmentation in tourism (e.g. Bigné \& Andreu, 2004). Indeed, across a range of contexts, our understanding of the role emotions play in determining important outcomes from tourism experiences and/or responses to tourist destinations is rapidly developing (Bigné, Mattila \& Andreu 2008; Hosany 2012; Ma, Gao, Scott \& Ding, 2013).

However, knowledge of how experiences engage emotions or how emotions work in channelling consumer activities in particular directions remains limited, despite calls for further investigation for some time (e.g. Holbrook \& Hirschman, 1982). The majority of recent research in tourism is based on the application of psychological scales developed to measure emotional responses; these are constrained in their ability to explain how tourist's consumption experiences lead to a particular emotional response (Ma et al., 2013). Therefore qualitative approaches may contribute a more nuanced understanding of the range of emotion experiences and how they might influence motivations for certain types of tourist behaviour. Specifically, qualitative approaches may enable a more fine-grained analysis of emotion. Hedonic response for example contains both positive (joy, pleasure) and negative (hubris, disgust) valence, for which qualitative approaches may be useful to explicate. One potentially fruitful context in which to explore these issues is ethical tourism.

Ethical tourism offers "emotional recreation" or a platform for liberation and 
emancipation driven by a consumer's desire to "feel good" (Goodwin \& Francis, 2003, p. 273). However, the link between hedonic emotions and ethical consumption practice is largely unexplored. Tourism is fraught with complex ethical issues, this fact has spawned a debate about the ethics of tourism development (Butcher, 2003; Smith \& Duffy 2003; Fennell, 2006). Simultaneously, a market has developed which attempts to differentiate tourism products and destinations as more ethically oriented within the rubric of sustainable, responsible, ecotourism, alternative tourism and many more labels (Goodwin \& Francis, 2003; Lansing \& DeVries, 2007; Caruana \& Crane, 2011). Whilst tourist's experiences of ethical/responsible tourism practices have attracted the attention of researchers, few efforts have focused on the role hedonic emotions play in ethical choice or in the tourism consumption experience.

This dearth of knowledge on ethical tourism experience and the emotions that drive it is the focus of this study. This paper aims to explore tourism experiences of consumers who self-identify as ethical tourists. Specifically, the study sought to understand the role of emotion in consumers' ethical choice and to investigate the relationship between pleasure and ethical tourism consumption experiences by exploring hedonic value in ethical tourism. The findings highlight the importance of emotion in influencing, motivating and reinforcing consumers' ethical choice, which offers important insights into tourist behaviour and implications for tourism management and marketing.

\section{EMOTIONS, ETHICAL CONSUMPTION AND ETHICAL TOURISM}

Definitions of emotion are somewhat fragmented in the literature. It is a psychological term that has been used quite loosely in many subject areas. Psychology draws a distinction between basic or visceral emotions (e.g. fear, anger) and self-conscious emotions (e.g. shame, guilt, pride). Emotions are psycho-physiological, they can affect our physical state but are also experienced as mental states, states that display immediacy and intensity. Emotions are real (as felt) but also subjective representations of an individual's being. It is perhaps this rather complex conceptual duality that has until recently limited the academic study of the role of emotion in hedonic consumption (Alba \& Williams, 2013). Tourism is inextricably related to pleasurable motives, and yet research has only recently begun to explore and apply methods to determine links between hedonic response and behavioural intentions and other issues (Gnoth, 1997). A major difficulty has been the subjective nature of emotional response, for example an experience might be richly emotional for one person and distinctly utilitarian for another (Alba \& Williams, 2013).

Hedonic consumption has been defined as the multisensory, fun and emotive aspects of consumer's experience of products (Hirschman \& Holbrook, 1982). Within tourism studies, the links between pleasurable emotions and satisfying outcomes are fundamentally important (Aho, 2001). Yet the focus for much research on the sensorial aspects of tourist experience, has been on a single sense, such as the 'gaze' (Urry \& Larsen, 2012), embodied performance (Veijola \& Jokinen, 1994), and the olfactory (Dann \& Steen-Jacobsen, 2002) with little connection between emotions and other sensory aspects of experience. Although the majority of research has focused on the visual senses, recognizing the important links between ocularcentrism, the visual representation of places, emotional engagement and behavioural intentions (Kim, 2012). A further strand of research has investigated the links between tourist 
experience and happiness (Nawijn, 2011) and as goal driven leading to increased levels of affect and subjective well-being (Sirgy, 2010). Destination marketing has long recognized the corporeal and multisensory nature of tourist experiences and has attempted to enrich promotional content with sensory illusions (Pan \& Ryan, 2009). There have been few links established between the phenomenological experience of emotion as a driver of behaviour, or between multi-sensory experiences, pleasurable outcomes and behaviour change.

There has been a recent surge in research in the role of emotion in tourism studies (Gnoth, 1997; Goossens, 2000; Hosany, 2012). Tourism consumption is often expressed through fantasies and dreams and continued through stories and holiday talk upon returning home (Pearce, 2009). Emotion tends to be viewed as an evaluative construct associated with: a) tourism destination loyalty [behavioural intentions] or emotional satisfaction (Mano \& Oliver, 1993; Bigné, Matilla \& Andreu, 2008; Hosany \& Gilbert, 2010), b) a response to complaint experiences (Schoefer \& Ennew, 2005), c) a segmentation tool based on the pleasure and arousal associated with leisure and tourism services (Bigné \& Andreu, 2004), or d) as a motivator for vacation choice or purchase decision behaviour (Goossens, 2000). However, despite the shortcomings identified with the application of conventional psychological emotional scales to tourism studies (Hosany \& Gilbert, 2010), there have been fewer qualitative studies that have explored emotions in the context of tourism experiences. The perspective on emotion adopted here is consistent with a phenomenological understanding of emotion (Solomon 1993, 2007; Goldie 2002, 2009). This approach centres on the emotional experience as described by the individual (e.g. Frijda, 2005; Barrett, Mesquita, Ochsner \& Gross, 2007) rather than measuring emotion as a psychological 'output', thus privileging the meanings and saliency of emotions in accounts of experiences.

The importance of emotions in ethical choice processes has been widely acknowledged in recent research (Steenhaut \& Van Kenhoven, 2006; Gaudine \& Thorne, 2001; Marks \& Mayo, 1991). Although these studies do not specify the role of emotion, the majority deal with the experience of emotions prior to consumption or as an outcome of the decision-making process. These studies suggest that negative emotions are experienced when an individual is faced with ethical dilemmas, such as a lack of ethical alternatives available, a lack of information, a price issue, or by feeling confused when faced with ethical terminology (de Pelsmacker, Driesen \& Rayp, 2005) often leading to feelings of guilt, which can "influence the consumer's future behaviour" (Marks \& Mayo, 1991, p. 721). An important issue here is the difference between emotional arousal and feeling state (valence) (Rest, 1979). This is because "ethical decisions often are emotionally charged; however, this does not necessarily suggest that the ethical decision process is not rational" (Gaudine \& Thorne, 2001, p. 175). It is claimed that high arousal and positive feeling states generate greater vigilance in situations where ethical dilemmas and reasoning are present, such as tourism, whereas low arousal and positive feeling state situations are less likely to recognise the occurrence of an ethical issue.

The notion that tourists ethical choices are influenced by the emotive aspects of the core consumption experience is relatively novel. Indeed, hedonism and ethical tourism can be seen as paradoxical or even antithetical (Buckley, 2012). Tourism choice is generally bound by hedonic motivations, as tourists inevitably seek out pleasurable activities (Gnoth, 1997; Goossens, 2000). However, ethical tourism is considered to be an act of 
compromise in the face of conflicting hedonic, social and environmental concerns (Fennell, 2006). Butcher (2003) suggests that the link between ethical tourism, fun and adventure is, more often than not, overshadowed by a new ethical imperative: "the association of tourism with innocence, fun and adventure, has been challenged by a mood of pessimism and a sense that moral regulation of pleasure-seeking is necessary in order to preserve environmental and cultural diversity" (p. 7).

The place of ethics in tourism studies is somewhat ambiguous. Many authors argue that ethical tourism is predicated on the concept of sustainable development (e.g. Butcher, 2003), and yet, its meaning is often met with varying interpretations. Often tourists have a limited understanding of the social and environmental impacts of tourism, but less insight as to how their behaviour could change things for the better (Miller, Rathouse, Scarles, Holmes \& Tribe, 2010). Some consumers tend to blame others, or the situation they are in and not themselves for their actions (Higgins \& Pittman, 2008). Many definitions of ethical tourism are narrow in their focus often concentrating on only one aspect of sustainability such as the environment. Additionally, notwithstanding the fact that tourism is a leisure activity, ethical tourism is not strongly associated with hedonic motivations. Thus, the role of hedonism in ethical tourism is largely unknown in what is otherwise defined as a virtuous, moral mode of tourism behaviour.

Soper (2008) and Soper, Ryle and Lyn (2009) have asserted that an alternative hedonism is emerging as individuals strive for the 'good life', a desire stemming from dissatisfaction with materialism and consumerism. They conclude that such choices are, in themselves, an hedonic experience. Likewise, Fennell (2006, p.71) maintains that "hedonism regards pleasure as the goal that renders participation in an activity worthwhile [...] allowing the individual to determine what is pleasurable". Although the concept of an alternative hedonism is in its infancy, some studies have noted that pleasure is often derived from an individuals' deliberate 'pious and worthy' choices (Schaefer \& Crane, 2005). Such choices are not based on rational ideas alone, but in many cases "our emotions more than reason, guarantee our commitment, and act as a basis for the moral choices we make" (Fennell, 2006, p. 40).

The role of non-rational factors in motivating ethical choice have been underresearched although socio-psychological explanations of contradictory behaviour have been developed (e.g. Chatzidakis, Hibbert \& Smith, 2007). Many authors (e.g. Gaudine \& Thorne, 2001; Marks \& Mayo, 1991) argue for the need to include emotion in ethical choice however this has yet to be considered comprehensively. Given that emotions can help resolve "what they [individuals] do and what they say, between what they do and what seems most appropriate [...] between what they do and what they profess to know they should do" (Frijda, 2008, p. 69), it is therefore important to explore the role emotions play in ethical tourism choice behaviour. It is in this context that the current study aims to examine the complex role emotions play, particularly focusing on the relationship between hedonic factors and ethical tourism experiences.

\section{METHODOLOGY}

This study adopts an interpretivist research approach to help uncover participants' subjective experiences, their meaning, and how respondents make sense of them. The 
study employs IPA (interpretative phenomenological analysis - Smith, 2008), based on the theory of hermeneutic phenomenology. IPA methods require an exposition of subjective experience, which makes it a particularly appropriate method to investigate the complexity of specific emotions in a sensitive and granular level of analytic detail. IPA has three theoretical bases: phenomenology; hermeneutics and an idiographic approach. A phenomenological study concentrates on the 'lifeworld' of the participant and the psychological meaning that constitutes that phenomenon (Smith, 2008).

To make sense of these phenomena, IPA uses interpretative method and particularly the theory of hermeneutics to help understand the conscious subjective experience of research participants. Thus, importance is not placed on the experience as it emerges, but more crucially, on how the participants ascribe meaning to and perceive lived experiences. More importantly, "IPA also recognises that access to experience is always dependent on what participants tell us about that experience, and that the researcher then needs to interpret that account from the participant in order to understand their experience" (Smith, Flowers \& Larking, 2009, p. 3). Thus a 'double hermeneutic' is applied as the researcher aims to interpret the sense of the participant who is also engaged in making sense of their experience. It is important to note that the participant's meaning-making of their experiences is always first-order to the researcher's sense-making (whilst bracketing any preconceptions). Studies in IPA adopt an idiographic focus on the particular, that is, a particular phenomenon in a particular context interpreted by a particular participant group. As a result, they offer "a deeper, more personal, individualised analysis" of experiences (Brocki \& Wearden, 2006, p. 99).

A critical issue that the researchers confronted was the subjective nature of 'ethical actions', and their relevance in a study of emotion in tourist experiences. Firstly, ethics provides an ideal lens through which to explore emotion, since it is the study of values. Hultsman (1995) argues "...it is possible to reach ethical perspectives from the experience of emotions, as one may feel morally moved when witnessing an act of kindness or cruelty." (1995, p. 554), and so ethical positions could provide a rich context to explore emotions. Secondly is the philosophical link between ethical tourism, authenticity and hedonism. Whilst space does not permit a detailed elaboration of the complex nature of these debates, our approach was informed by the phenomenological perspective on hedonism as existential authenticity.

Thus tourist choices are self-determined, based on freedom of choice, in the pursuit of personal authenticity (Fennell 2009). This is in distinction to a teleological perspective of behaviour driven by a search for flourishing, Aristotelian eudaimonia, and hence instrumental or reasoned. Ethical experiences we hoped would lead us to tourists who were driven by a search for existentially authentic experiences which for Rickly-Boyd "...results in a preoccupation with feelings, emotions, sensations, relationships, and self" (2012, p. 273), which connected with our phenomenological orientation, as opposed to constructionist or mediated approaches to the determinants of emotion in tourist spaces such as the Benjaminian perpective on authenticity and 'aura' (ibid).

Thus, it was important that participants self-identified (as opposed to researcherdetermined) as ethical tourists and were fluent in English due to the nature of the indepth, conversational interview technique and a need to interrogate emotions in 
experiences within the context of no universal definition of emotion (Lazarus, 1995). IPA studies are purposeful, in that they select a particular participant group and focus on a particular research question or issue to develop a full and descriptive interpretation of the issues through a micro-level analysis. Thus, a relatively homogeneous participant set was required, for whom the issue or context of study has significant personal relevance.

To access self-defined ethical tourists, the researchers identified many online and offline 'ethical tourism/traveller groups' in the Republic of Ireland. Access was negotiated so that a call for potential participants could be launched through their social networking sites. After purposively selecting the participants from those who responded to the adverts, the researcher requested referrals from them of any colleagues and friends who were willing to take part in the research. This process led to thirteen participants being recruited for the study, whose profiles are provided in table one. Many of the respondents talked about visits to the Burren GeoPark as the locus for their accounts of ethical tourism behaviour, which was widely mentioned in the interviews. However, this particular place was not the basis for selection of respondents.

\section{INSERT TABLE 1 HERE}

In terms of method, a semi-structured interview approach was adopted with the aid of an interview schedule. The interview schedule complements phenomenological protocols, which have been developed to allow the interviewer to apply depth probing to uncover rich information in the form of stories, examples and accounts of how participants understand their experiences, with the aim that aspects of the participants life-world emerges through the interviewing. This is a flexible, loosely-structured process. Each interview lasted approximately 90 minutes and took place either in the participant's home or a location of their choice e.g. local libraries.

The data collection was carried out case by case over a two and half-month period to allow the researcher time to reflect on each interview and make any necessary amendments to the interview schedule and techniques employed. All interviews were recorded using a digital voice recorder with the permission of the participants. Interview data was transcribed using pseudonyms to ensure anonymity. The topic of conversation regarding tourism locations/destinations was not concealed as this data was considered to be integral to the research context. Once the data was collected and transcribed, the analytic process followed the guidelines outlined for IPA (Smith, et al., 2009) as well as Braun \& Clarke's (2006) thematic analysis steps. The data analysis process focused on developing an understanding of the phenomenon under investigation through interpretation, not only of what it is, but on what it means (i.e. a double hermeneutic). This was an iterative process and followed an inductive cycle as many stages were repeated and in some instances, going back to original transcript was necessary to ensure meaning was accurately represented. Finally, thematic groups were formed and given a descriptive label that conveyed the conceptual nature of the themes within.

An IPA study does not make claims of generalizability; it aims to achieve theoretical transferability, as opposed to theoretical saturation. This is because saturation relates 
to a specific point at which no new theoretical insights are evident on a particular topic or theme. IPA instead seeks to produce a clearly situated, circumscribed and transparent account of what has been found within a particular research context. This can enable the transfer of meaning to new phenomena in similar contexts or to related phenomena in new contexts (Guba \& Lincoln, 1985). Therefore it does not claim to discover everything possible in one study as emphasis is placed on topic saturation. Thus, IPA reflects Hyde's (2003, p. 48) notion of theme saturation where "no new data is added because that category has been adequately explained", that is, "coding and analysis end when theme saturation occurs" (Bowen, 2008, p. 140).

In this study, emphasis was placed on the subjective representation of an individual's emotional experiences, expressed through feeling states commensurate with a phenomenological perspective of emotion (Solomon, 1993, 2007; Goldie, 2002, 2009). Although emotions arise in the field of social experience, their referent is always back to the self that feels (Heidegger, 1975). This study aimed to develop an understanding of the inner emotional experiences of tourists to help explain important social interactions and new perspectives for understanding tourists' experiences. Defining emotion as a personal experience that is content rich and context specific, it requires in-context examination in order to gain greater understanding and meaning. This perspective takes into account the actual experience of emotion often communicated through emotional feelings. To probe emotion experiences the interviewer used direct questions such as 'can you tell me how this made you feel?' These questions helped the participants to describe and offer meaning to their experiences on an emotional level.

\section{FINDINGS AND DISCUSSION}

The findings indicated that participants not only expressed a desire to engage in market place activities as a means of reflecting their ethical beliefs and values, but they also described the emotive aspects of the core consumption experience. A positive link between emotional experiences and ethical consumption choice became evident. In particular, the motivating and reinforcing role of emotion in self-defined ethical tourist choice was identified. The following section describes the role of emotion in motivating and reaffirming ethical choice. The second section identifies the integral role of emotion as part of the consumption experiences as a source of hedonic value.

\section{THE MOTIVATIONAL ROLE OF EMOTION IN ETHICAL CHOICE}

The role of emotion in motivating ethical choice has two fundamental manifestations: the reinforcing role of positive emotions and the positive role of negative emotions. A typical account of these issues is offered by Fiona, who talked about a mountain hike in the 'Burren GeoPark' in Ireland. Early in her conversation, she described the effect of her experience in relation to a self-defined ethical hike taking place the following morning. The ethical premise of her choice is based on the fact that it was (1) a domestic holiday, and (2) the location of this activity is significant as it emphasises the ethical foundation of Fiona's decision-making process, due to its recognition as an active area of preservation, which encourages tourists to be responsible. In response to being asked why she chose this holiday, she expresses the motivational role of anticipated enjoyment as impacting on her choice as: 
"I get my motivation from the enjoyment I get from doing these activities and pastimes, as in, I feel better, I feel healthier, my mind feels free when I am enjoying these pastimes". (12-14)

For Fiona, this experience highlights the pivotal role of emotional experience in the preconsumption stage in influencing her choice. This anticipated emotion can be interpreted as a pull motivation factor based on the destination's attributes, as Fiona's choice is bound by the promise of an enjoyable experience. This experience, in turn, contributes to her expectation formation and ultimately her satisfaction (Gnoth, 1997) as she demonstrates the motivational role of emotion as a central part of the coreconsumption experience, by claiming "my mind feels free when I am enjoying these pastimes". As a result, Fiona's overall experience is intensified as her ethical tourism choice is not simply motivated by the enjoyment these experiences bring, but also through the fact that these emotional episodes add value to the overall consumption encounter. It is probable that Fiona's internal desire for enjoyment is a push factor motivating her choice in the first instance. In this case, both push and pull motivational factors are experienced simultaneously, influencing her choice. According to Gnoth (1997, p. 285) "those values which are under strong emotional influence, the objective locus of control lies within the person as he/she produces those emotions". Thus, if Fiona's desire to be emotionally stimulated is satisfactorily met, then it is likely that she will employ the same behaviour again (ibid). Fiona continues to talk about the reason for her choice by illustrating the value of these experiences as expressed through the emotional benefits bestowed:

"I haven't done this particular hike before but I am sure it will be full of fun and surprises. No two experiences are ever the same, no two walks are ever the same. It (ethical tourism) is always exciting and full of surprises." (301-302)

"I think you are feeding your soul by going and exposing yourself to all these new things. I don't think you can feed your soul in Lanzarote [LAUGHING]. It's the unknown as well -- it's exhilarating really." (323-324)

Fiona expresses the idea of an enjoyable experience that exceeds satisfaction alone. By "going and exposing yourself", she suggests that personal effort is required to seek out and discover these value-laden encounters. That is not to say that other tourism experiences are not value-laden, but for her, this experience is meaningful as the outcome leads to emotional benefits, which she expressed through feelings of surprise and exhilaration. Such encounters demonstrate the complex, subjective nature of emotion experiences and exemplifies the limitations associated with basic and discrete emotion sets and their inadequacy for consumption emotion research (Richins, 1997). That is, basic emotions do not take into account a wide range of emotions often experienced in consumption settings, neither do they differentiation between emotions with similar valence such as happiness or joy. Often individuals experience different emotions evoked by the same encounter (Barrett \& Gross, 2001) and can interpret similar emotions differently with varying intensities. This is due to the fact that subjective experiences create meanings and relationships that are phenomenologically and contextually determined. Therefore, emotional experiences cannot be reduced to 'bodily states' alone (Frijda, 2008). 
For Fiona, feelings of surprise and exhilaration are intense emotional encounters as she links these with a sense of challenge and excitement, indicated by the phrase "exposing yourself". As a result, she claims to reap the benefits of this experience in terms of personal growth, through "feeding your soul". This encounter appears to exceed her expectations which is evident from her apparent surprise at the emotional value of the experience: "it's exhilarating really". Thus, it is implied that the connection between the emotions felt, and the consumption experience lead to a deeply engaging encounter. Such experiences can result in an augmented tourism experience as emotions often lead to a higher pleasure or superior-quality experience (Campbell, 1989).

In some cases, the participants demonstrated the motivational role of negative emotions in influencing their ethical choices. Many stated that they tended to avoid destinations associated with mainstream tourism because of implied feelings of disgust or hubris. This is demonstrated by Graham as he claimed:

"I will avoid certain areas like in Carrantuohill and Croach Patrick because of all the damage that has happened to the mountain because they are not properly managed. What takes away from the experience for me is (.) the litter on it (.) and the amount of litter and crap left lying around just really takes away from the experience because that is not a part of the mountain; that is someone, a human, their impact and not thinking about the impact that has." (116-122)

Graham conveys the idea of having an inferior experience due to a lack of consideration from others, and feelings of sadness and potentially anger are suggested. Graham not only avoids these areas, he alludes to feelings of disgust at the impacts of tourist activities. Although these emotions arise in a social context, Graham feels them. However, rather than being evoked due to his behaviour, these emotions are directed at the behaviour of others. According to Pleumarom (1995), decisions such as Graham's, aimed at seeking out alternative areas due to the degradation of certain tourism destinations, epitomises the irony embedded in ecotourism-style offerings. That is, knowingly or unknowingly, the desire to experience an undamaged, unpolluted environment ultimately leads to a damaged and polluted one. This is because the unpolluted areas often become elite or prestigious attractions, thus bringing many 'alternative tourists'.

Graham displays the classic moral neutralisation technique of denial of responsibility. He does not seem to view his actions as irresponsible or as having any part to play in the damage caused in these areas. This is despite the fact that he may be damaging the mountain himself by climbing it. As the conversation continued, Graham claimed that mainstream tourists lack the knowledge required to appreciate their natural environment. He infers that this, in turn, causes a lack of appreciation for, or engagement with, the surrounding environment. Such sentiments led to a sense of superiority which we interpret as hubris. These emotions, expressed through feelings of arrogance or superiority, can impede moral behaviour as individuals tend to view themselves in a superior light and above reprieve (Lewis, 2000). Although they are elicited due to social experiences, they can result in a deviation from one's moral etiquette and social standards as individuals "distort and invent situations to enhance the self” (Tangney, Stuewig \& Mashek, 2007, p. 360). Graham's negative feelings are 
outward directed aimed at mainstream tourists, as he professes:

"Sometimes I think it [is] almost a bit of a god-like complex on people's parts as they think they are in some ways better than nature. Sometimes it is ignorance too. They [mainstream tourists] are actually not part of it, they are not seeing the whole picture, it [is] just, like, 'well do you know how long that [rubbish] is going to stay there for?' Often I think it is a question of education. They don't value the environment. It's like people taking photographs and saying 'isn't this amazing' and then they chuck a bottle. It's like they are standing on that mountain over there, but this mountain is amazing but they are not seeing that. They are not taking in their immediate surroundings or not appreciating it." (138-146)

Feelings of superiority were frequently expressed through the participants' accounts in relation to their experiences and choices. This tended to stem from the level of the participants' emotional engagement with the experience itself. From this perspective, the participants referred to feelings of snobbery and detachment, highlighting the subjective nature of an enjoyable experience in an ethical tourism context. For instance, Lorraine defends her ethical choice in the following extract:

L: "They (ethical holidays) are not sun and sand, they are real, you know, they are different and cultural; you suddenly realise those are the sorts of holidays you are booking."

I: "Can you describe why this is?"

L: "I'd say it's 'cause I'm a snob; I'd say I am a tourism snob." (174-180)

"I don't know ifyou like to feel that you are amongst the travelling elite or that it's an authentic experience or, (.) I would just have no interest in sun and sand at all." (202-203)

Lorraine's statement is a subjective evaluation of all the mainstream tourism holidays she has taken. She is aware of her likes and dislikes as she expresses a sense of superiority when talking about her choice of ethical tourism, thus separating herself from others as she claimed to be a 'tourism snob' and part of the 'travelling elite'. These kinds of personal assessments and associated feelings resulted in many tensions across the participants' accounts as most of them tended to perceive their experiences as different. From this perspective, mainstream tourism is described as a standardised offering, lacking engagement, novelty, surprise and emotional elicitation. This calls into question what constitutes an enjoyable experience as it implies that enjoyment is a subjective state that is determined by the individual. It became apparent that enjoyable experiences are those that are engaging on a personal and an emotional level, which, in most cases, complements a perceived ethical sense of self as exercised through consumption practices.

\section{EMOTION: A SOURCE OF ENJOYMENT}

Many participants identified the role of emotion as source of hedonic value experienced 
during their ethical tourism encounters. This strengthens the notion that emotions have an important role to play in influencing and motivating ethical choice as well as shaping consumers' ethical tourism consumption experiences. This section seeks to address the source and meaning of hedonic value in an ethical consumption context. It was evident from this study that there are two main sources of hedonic value: accounts of mutual benefit and freedom as an affective state.

\section{Accounts of Mutual Benefit}

A source of hedonic value in ethical tourism is evident in the emotions expressed by those who participate in an exchange relationship. This is where an emphasis is placed on a reciprocal relationship, from which both the visitors and the host destination receive a mutual benefit. Laura reveals this type of idea as she talks about the meaning of ethical tourism in general. She describes these experiences as bound by a reciprocal relationship between herself and the host destination. The following extracts, drawn from the beginning and the end of the interview respectively, highlight her definition of a reciprocal relationship:

"In a village which relies on tourism as an income, then the social side of tourism is pretty important, to make sure that the income from tourism goes directly into the pockets of those people who are, say, producing the items or selling items in that destination. So there are different mixes in different destinations and I guess as a person I would suggest that ethical tourism is about considering what the impacts of our travels are around the world or wherever that might be" (6-12)

"I realise it was not about just getting something out of your travels itself but it is also about giving something back. It makes me feel good." (46-48)

You can support small shops and suppliers in a village rather than go to a supermarket. It is just taking into consideration of who lives there, how to support local industries and, um, taking time to understand a bit about the local people and landscapes." (324-330)

Laura emphasises the need to ensure that the money she spends while visiting an area is received by the local people. Indeed, the exchange relationship she mentions highlights the foundation of her ethical choice, in terms of reflecting her ethical beliefs and values. Here, Laura is demonstrating the importance of reciprocity. Miller et al. (2010) suggest that a sense of personal responsibility is essential in creating and maintaining a sustainable tourism industry. It can be argued that, by taking part in a reciprocal act, the participants are empowered.

Similar to Butcher's (2003) "new moral tourist" concept, Laura implies a differentiation between her tourism experience and sense of self as she refers to taking responsibility as a tourist as evident in her awareness of "the impacts of our travels". Such experiences are emotionally rewarding as she claims "it makes me feel good". In this sense, she is describing a sense of empowerment, obtained through her consumption choice.

However, it is also conceivable that Laura's efforts are a preventative measure, aimed at averting the negative emotions often associated with tourism consumption. In other 
words, ethical choice is a feel-good, guiltless experience offering an alternative type of hedonism (Soper, 2008). Laura illustrates how these encounters make her feel:

"On a personal level, I am aware that my travels do have an impact and I want to make sure it is as positive an impact as possible. (.). By its own admission, that means that you often get to know, well, by caring about the traceability of a product, you get to know who makes it, so if you get to know who makes a product then you get to know a person so (.), often those sorts of travels are about people and meeting other people. So there is always an exchange ... So, um, I guess it's being open to that kind of exchange that leads people to believe that ethical tourism is more of an authentic experience rather than a superficial one where you are in and out of the place butyou don't really learn anything. " (16-27).

Similarly, Jackie refers to the positive effect of taking part in an exchange relationship by hiring local tour guides while abroad. For Jackie, the ethical premise of her choice was based on a desire to support local businesses in the host community [South America]. She states:

"I do, I guess, try to favour companies that utilise the local population as much as I can because that is good for everybody, and then I don't feel as guilty." (45-47).

"Some tour operators offer where you can plant a tree to offset your carbon footprint, but I don't. I try and do things when I am there." (54-56)

The decision to use local operators enhances Jackie's overall experience and a mutual benefit is obtained. In addition, this reciprocal relationship has a ripple effect in the local community on an economic and social level, as Jackie's approach helps support and empower local businesses and potentially helps to reduce social tensions by developing relationships with local people. Jackie's motivation to participate in an exchange relationship is driven by the enjoyment it bestows on her. Thus, the emotive aspects of consumption are self-focused as Jackie aims to alleviate feelings of guilt by taking part in an exchange relationship.

According to Hirschman \& Holbrook (1982), hedonic consumption is often associated with an imaginative construction of reality, that is, not what a consumer knows to be real but rather what they desire to be real. As Jackie chooses to go to South America, this has a negative impact on the environment in terms of carbon emissions. It is therefore reasonable to believe that Jackie is, in a sense, constructing a desired ethical reality beyond its objective context. Although Jackie experiences positive emotions from giving as well as receiving, taking part in an exchange relationship acts as a coping mechanism, which alleviates her feelings of guilt over the negative impacts of flying. This demonstrates the subjectivity of ethical consumption experiences and the complex interplay between hedonic value and ethical practices. Ethical beliefs alone are not enough to drive ethical behaviour, however, Steenhaut \& van Kenhove (2006) claim that emotions such as guilt are often more effective drivers of ethical behaviour than positive emotions. In summary, emotional experiences provide a source of hedonic value and are fundamental motivators of and reinforcement mechanisms for consumers' ethical behaviour. 


\section{Freedom as an Affective State}

The participants' feelings of freedom stemmed from two sources. First, 'freedom from' relates to an escape, generally from everyday life. It is a form of liberation as individuals escape negative stimuli present in their daily lives. Second, freedom is an emotion felt in the process of consumption and is a source of hedonic value expressed through positive experiences (Kane \& Tucker, 2004). In this case, the notion of 'freedom to' refers to a need to have a pleasurable ethical tourism experience. In both instances, freedom relates to a desire to express one's ethical beliefs and values through consumption practices and to take part in experiences that complement those beliefs and values. For Mary, feelings of freedom relate to many things. First, she talks about herself, as well as, on behalf of her husband when referring to a cycling and camping trip to France. These encounters are not always an emotion-based experience per se; they can be action-or behaviour-related. In the following extracts, Mary refers to the freedom associated of her trip as:

M: "You are around people all day, and you want to get away from crowds, um, and you want to kind of, um, understand how people live outside, and how they live differently. We know we have to live in cities for the time being so it is good to kind of have something different away from that." (178-181)

I: "What does this mean to you; how does it make you feel being in the outdoors?"

M: "I guess, um, we both, after a few days, we both felt not particularly clean [LAUGHING], but we didn't care. You know, it is not about, it is no longer about appearances. You just kind of get on with it and enjoy the fresh air and you just don't really get that at home. Yeah and it was great to, there was just a handful of people there and you felt that you had your own space and your own time to just, kind of, really, um, have time to think as well."

\section{I: "Is that a one-off experience for you?"}

M: "No it's not. Me and my husband tend to travel together so (.), we both want to get away and have the freedom to do that, so it's not a one-off, we do this regularly ... it was a real kind of refresh and it feels really good." (186-200) ... "We are not hikers so much but we both love cycling ... it is the freedom of that and being able to go wherever you want to go". (212-213)

Mary demonstrates the enjoyment of being away "from everyone and everything" and able to "go wherever you want to go". It is the emotions stemming from these experiences that augment her overall encounter as "it was a real kind of refresh and it feels really good". It can be argued that all tourism experiences provide a sense of escape and tourists' experience are often associated with feelings of freedom (Iso-Ahola, 1979), however, a distinction is offered in this study. Despite the fact that the participants refer to 'freedom from' (an escape) and a sense of 'freedom to' (make choices and to explore), the emphasis is placed on 'what it feels like', that is, freedom as an affective state; the emotions felt in the process of consumption leading to a 'freedom experience'. Such feelings are associated with ethical tourism choices. 
However, that is not to say that all ethical tourism encounters offer freedom experiences. Butcher (2003) refers to the restrictions embedded in an ethical tourism choice arguably based on Kantian normative ethics or Feuerbach's notion of freedom. In this case, ethical tourists are inescapably committed to certain standards and practices; consequently, one's freedom is restricted. Our existentialist perspective interprets freedom as not only experienced in terms of the choice made but also in the experience itself. It is conceivable that the emotions experienced relate to and stem from a person's desire to have a pleasurable experience. These feelings are not only linked to the idea of tourism as a perceived escape experience or the freedom to take part in escape behaviour; they are an essential and intrinsic aspect of the experience that adds value to the overall encounter. Hence, freedom acts as a hedonic value that augments the participants overall experience in ethical tourism encounters.

Similarly, Sinead talks about her ethical tourism choice as providing a getaway from everyday life, and the desire to be "anywhere there is less human impact or buildings". In Sinead's case, these encounters are not only desired for escape purposes, they are sought after because of how they make her feel. The ethical basis of her choice is founded on the fact that it is a domestic walking holiday in an active area of preservation. She describes the motivating role freedom played in her choice of holiday in the following extract:

S: "I like going walking for the reason of getting away from the hustle and bustle of um (.), people and like getting out into the quiet." (61-63)

I: "Can you tell me how this makes you feel?"

S: "It's like it recharges my batteries, it makes me feel good. I just feel so much better. I just feel (.), I just like (.) there is nothing better than just standing out in the outdoors and breathing it all in. It's the experience of the whole thing." (72-77)

Sinead describes the benefits of her encounter as stemming from the positive emotion she feels in the process of consumption, evident in her assertion: "it makes me feel good. I just feel so much better". For Sinead, the experience of being outdoors, just standing and breathing, are akin to a process of rejuvenation, recharging batteries. Being in the wild, away from other humans and human activity is interpreted as a positive emotion eliding with a sense of freedom and an ethical sense of self. Freedom, for Sinead, refers to an escape, demonstrating a link between being in nature and feelings of rejuvenation similar to those evident in Arnold \& Price's (1993) study. Thus, feelings of freedom act as a hedonic value in ethical tourism, emanating from the emotions felt in the process of consumption.

In sum, freedom is a fluid concept; it can mean many things to many people. Caruana \& Crane (2011) claim that a source of hedonistic value in ethical consumption in a tourism context is often expressed as an 'escape' experience. However, in this study, the motivation for these experiences stemmed from the concomitant feelings of freedom, that is, the 'freedom to' explore and participate in co-producing a tourism experience and possible 'freedom from' feelings of guilt associated with mainstream tourism encounters. It is therefore plausible that the freedom associated with an ethical alternative leads to the association of ethical tourism as a 'freedom-experience'. 


\section{CONCLUSIONS}

There is little extant research into how emotions are expressed, interpreted or integrated into tourists' experiences. This is despite the overwhelming evidence concerning the emotional aspects of tourism encounters (e.g. Pearce, 2009). This study has tried to move the debate forward towards a greater understanding of the hedonic value of ethical tourism consumption experiences. The findings demonstrate the motivational and reinforcing role that emotions play in consumer's ethical choice formation. Specifically, the study identified the positive role of negative emotions such as hubris and disgust in reaffirming ethical choice through a process of separation, and its implications for current and intended ethical behaviour is evident. These findings are important given the lack of understanding with regard to consumers' ethical decision-making process. Therefore, the findings contribute to ethical theory and the consumer behaviour literature by demonstrating the pivotal role of emotion in consumers' ethical choice formation.

Ethical tourism is a pleasure-seeking activity. The respondents' spoke about their experiences as exchange relationships and identified the reciprocal benefits to themselves and others resulting from these encounters a source of hedonic value. They further identified tourism as an escape experience and the concomitant feelings that were identified with positive emotions. Although tourists are emotionally involved in the tourism experience and the emotive aspects are specifically sought after and appreciated, the findings highlighted the subjective nature of hedonic consumption, as individuals interpreted their own meanings of what is pleasurable. The subjective nature of ethical tourism experiences and the complex interplay between hedonic value and ethical practices is noteworthy given the limited understanding of ethical practices and hedonic motivations. This study advances our current understanding of ethical tourism experiences by demonstrating the integral role emotion plays in these consumption practices as a source of hedonic value and its role in motivating and reinforcing ethical choices. Furthermore, as individual's derived pleasure not only from deliberate moral choices (Schaefer \& Crane, 2005), but also from how the experiences make them feel, thus hedonistic and rational motivations for ethical choices have become intertwined. Consequently, current definitions and future interpretations of ethical tourism must be revised to take into consideration the role of pleasure (hedonism) in ethical choices and ethical tourism experiences, addressing Fennell's call for a "stronger understanding of values and how values link to ethics...should better prepare us in considering what we ought to do in order to be responsible or ethical in tourism" (2009, p. 224).

From a practical point of view the findings offer implications for management and policy. An understanding of the role emotions play in consumer's ethical decisionmaking process can facilitate the production of customised ethical tourism offerings (pull motivation). If emotions influence, motivate and reinforce ethical choice as push motivation factors, organisations can aim to develop emotional attachment through promoting the emotional experience associated with specific destinations as a means to engage customer loyalty and commitment (Hosany \& Gilbert, 2010). As a result, greater customer retention may follow as consumers move from being merely interested, to advocates of the organisation. Finally, greater knowledge of the role of emotion in 
consumers' ethical decision-making allows for a more sophisticated consumer segmentation process (Bigné \& Andreu 2004) aimed at developing long-term commitment with existing ethical consumers, and develop new strategies targeting potential new customers. This study provides insights that could be used to inform marketing communications that encourage pro-environmental behaviour. Additionally, an understanding of consumers' ethical tourism experiences and the motives for such practices is important from a social marketing and policy perspective to help encourage continued ethical behaviour, potentially change behaviour and to shape the future of the tourism industry.

\section{REFERENCES}

Aho, S.K. (2001). Towards a general theory of tourist experiences: modelling experience process in tourism. Tourism Review, 56(3), 33-7.

Alba, J.W. \& Williams, E.F. (2013). Pleasure Principles: a Review of Research on Hedonic Consumption. Journal of Consumer Psychology, 23(1), 2-18.

Arnould, E., \& Price, L. (1993). River Magic: Extraordinary Experience and the Extended Service Encounter. Journal of Consumer Research, 20, 24-45.

Barrett, L. F., \& Gross, J. J. (2001). Emotion representation and regulation: A process model of emotional intelligence. In Mayne, T. and Bonnano, G. (Eds.), Emotion: Current Issues and Future Directions (p.286-310). New York: Guilford

Barrett, L.F., Mesquita, B., Ochsner, K.N., \& Gross, J. J. (2007). The Experience of Emotion. Annual Review of Psychology, 58, 373-403.

Bigné, E.J., \& Andreu, L. (2004). Emotions in Segmentation: An Empirical Study. Annals of Tourism Research, 31(3), 682-696.

Bigné, E.J., Matilla, A.S., \& Andreu, L. (2008). The impact of experiential consumption cognitions and emotions on behavioural intention. Journal of Service Marketing, 22(4), 303-325.

Bowen, G. A. (2008). Naturalistic inquiry and the saturation concept: A research note. Qualitative Research, 8(1), 137-152.

Braun, V., \& Clarke, V. (2006). Using thematic analysis in psychology. Qualitative Research in Psychology, 3(2), 77-101.

Brocki, J.M., \& Wearden, A.J. (2006). A critical evaluation of the use of interpretative phenomenological analysis (IPA) in health psychology. Psychology and Health, 21(1), 87-108.

Buckley, R. (2012). Sustainable tourism: Research and reality. Annals of Tourism Research 39(2), 528-546

Butcher, J. (2003). The moralisation of tourism: sun, sand ... and saving the world? 
London: Routledge

Campbell, C. (1989). The Romantic Ethic and the Spirit of Modern Consumerism. Oxford: Blackwell Publishers.

Caruana, R., \& Crane, A. (2011). Getting away from it all. Annals of Tourism Research, 38(4), 1495-151.

Celsi, R.L., Rose, R.L., \&. Leigh, T.W. (1993), An Exploration of High-Risk Leisure Consumption Through Skydiving. Journal of Consumer Research, 20(1) 1-23.

Chatzidakis, A., Hibbert, S., \& Smith, A. (2007). Why People Don't Take their Concerns about Fair Trade to the Supermarket: The Role of Neutralisation. Journal of Business Ethics, 74(1), 89-100.

Dann, G.M.S., \& Jacobsen, J.K.S. (2002). Leading the tourist by the nose. In G. M. S., Dann, (Ed.) The tourist as a metaphor of the social world (pp. 209-235). Wallingford: CAB International.

de Pelsmacker, P., Driesen, L., \& Rayp, G. (2005). Do Consumers Care about Ethics? Willingness to Pay for Fair-Trade Coffee. Journal of Consumer Affairs, 39(2), 363-385.

Fennell, D.A. (2006). Tourism Ethics. Clevedon, UK: Channel View Publications.

Fennell, D.A. (2009). Ethics and Tourism. In J. Tribe (ed.) Philosophical Issues in Tourism, (pp 211-226). Bristol: Channel View.

Frijda, N.H. (2005). Emotion experience. Emotion and Cognition, 19, 473-494.

Frijda, N.H. (2008). The Psychologists' Point of View. In M. Lewis, J. M. Haviland-Jones, and L. F. Barrett (Eds.) Handbook of Emotions, $3^{\text {rd }}$ ed. London: The Guildford Press.

Gaudine, A., \& Thorne, L. (2001). Emotion and Ethical Decision-Making in Organisations. Journal of Business Ethics, 31(2), 175-187.

Gnoth, J. (1997). Motivation and Expectation Formation. Annals of Tourism Research, 24(2), 283-304.

Goldie, P. (2002). The emotions. A philosophical exploration. Oxford: Clarendon Press

Goldie, P. (2009). Getting feelings into emotional experiences in the right way. Emotion Review, 1(3), 232-239.

Goodwin, H. \& Francis, J. (2003). Ethical and Responsible Tourism: Consumer Trends in the UK. Journal of Vacation Marketing, 9(3), 271-282.

Goossens, C. (2000). Tourism Information and Pleasure Motivation. Annals of Tourism Research, 27(2), 301-321. 
Guba, Y.S., \& Lincoln, E.G. (1985). Naturalistic inquiry. Beverly Hills, CA: Sage.

Heidegger, M. (1975). The basic problems with phenomenology (A. Hofstader, Trans.). Bloomington: University of Indiana Press

Higgins, E.T., \& Pittman, T.S. (2008). Motives of the Human Animal: Comprehending, Managing, and Sharing Inner States. Annual Review of Psychology, 59, 361-385

Hirschman, C.E., \& Holbrook, B.M. (1982). Hedonic Consumption: Emerging concepts, Methods and Propositions. Journal of Marketing, 46, 92-101.

Holbrook, B.M., \& Hirschman, C.E. (1982). The Experiential Aspect of Consumption: Consumer Fantasies, Feelings and Fun. Journal of Consumer Research, 9, 132-140.

Hosany, S., \& Gilbert, D. (2010). Measuring tourist's emotional experiences toward hedonic holiday destinations. Journal of Travel Research, 49(4), 513-526

Hosany, S. (2012). Appraisal Determinants of Tourist Emotional Responses. Journal of Travel Research, 51(3), 303-314.

Hultsman, J. (1995). Just Tourism: An ethical framework, Annals of Tourism Research, $22(3), 553-567$.

Hyde, C.A. (2003). Multicultural Organization Development in Nonprofit Human Service Agencies: Views from the Field. Journal of Community Practice, 11(1) ,39-59.

Iso-Ahola, S. (1979). Basic Dimensions of Definitions of Leisure. Journal of Leisure Research, 11, 28-39

Kane, M.J., \& Tucker, H. (2004). Adventure tourism: The freedom to play with reality. Tourist Studies, 4(3), 217-234.

Kant, I. (1998). Groundwork of the Metaphysics of Morals, M. Gregor (Ed.). Cambridge University Press

Kim, S. (2012). Audience involvement and film tourism experiences: Emotional places, emotional experiences. Tourism Management, 33(2), 387-396.

Lansing, P., \& DeVries, P. (2007). Sustainable Tourism: Ethical Alternative or Marketing Ploy? Journal of Business Ethics, 72(1), 77-85.

Lazarus, R.S. (1995). Vexing Research Problems Inherent in Cognitive-Meditational Theories of Emotion-and Some Solutions. Psychology Inquiry, 6(3), 183-196.

Lewis, M. (2000). Self-conscious emotions: Embarrassment, pride, shame, and guilt. In M., Lewis \& J.M., Haviland-Jones (Eds.), Handbook of emotions 2nd ed., (pp. 623-636). New York: Guilford Press.

Ma, J., Gao, J., Scott, N., \& Ding, P. (2013). Customer Delight from Theme Park 
experiences: The Antecedents of Delight based on Cognitive Appraisal Theory. Annals of Tourism Research, 42, 359-381.

Mano, H., \& Oliver, L.R. (1993). Assessing the Dimensionality and Structure of the Consumption Experience: Evaluation, Feeling, and Satisfaction. Journal of Consumer Research, 20 (December).

Marks, J. L., \& Mayo, M. (1991). An Empirical Test of a model of Consumer Ethical Dilemmas. Advances in Consumer Research, 18, 720-727.

Miller, G., Rathouse, K., Scarles, C., Holmes, K., \& Tribe, J. (2010). Public Understanding of Sustainable Tourism. Annals of Tourism Research, 37(3), 627-645

Nawijn, J., (2011). Determinants of Daily Happiness on Vacation. Journal of Travel Research, 50(5), 559-566.

Pan, B., \& Ryan, C. (2009). Tourism Sense-Making: The Role of the Senses and Travel Journalism. Journal of Travel and Tourism Marketing, 26(7), 625-639.

Pearce, P.L. (2009). The Relationship between Positive Psychology and Tourist Behaviour Studies. Tourism Analysis, 14, 37-48.

Pleumarom, A. (1995). Ecotourism or Ecoterrorism?. Retrieved December $05^{\text {th }} 2011$, from Untamed Path website: http://www.untamedpath.com/Ecotourism/ecoterrorism.html.

Rest, R.J. (1979). Moral Judgment Research and the Cognitive-Developmental Approach to Moral Education. The Personal and Guidance Journal, 58(9), 602-605.

Richins, L.M. (1997). Measuring Emotions in the Consumption Experience. Journal of Consumer Research, 24, 127-146.

Rickly-Boyd, J. (2012). Authenticity \& Aura: A Benjaminian Approach to Tourism, Annals of Tourism Research, 39(1): 269-289.

Schaefer, A., \& Crane, A. (2005). Addressing Sustainability and Consumption. Journal of Macromarketing, 25(1), 76-92.

Schoefer, K., \& Ennew, C. (2005). The impact of perceived justice on consumers' emotional responses to service complaint experiences. Journal of Services Marketing, 19(5), 261-270.

Sirgy, M. (2010). Toward a quality-of-life theory of leisure travel satisfaction. Journal of Travel Research, 49, 246-260.

Smith, J. (2008). Qualitative Psychology: A Practical Guide to Research Methods $2^{\text {nd. }}$ London: Sage Publications.

Smith, J.A., Flowers, P., \& Larking, M. (2009). Interpretative Phenomenological Analysis: 
Theory, Method, Research. London: Sage Publications.

Smith, M., \& Duffy, R. (2003). The Ethics of Tourism Development. London: Routledge.

Solomon, R.C. (1993). The Passions. Emotions and the Meaning of Life. IndianapolisCambridge: Hackett Publications.

Solomon, R.C. (2007). True to our Feelings. What our emotions are really telling us. New York: Oxford University Press.

Soper, K. (2008). 'Alternative Hedonism' and the Citizen Consumer. In K. Soper \& F. Trentmann (Eds.) Citizens and Consumption (pp. 191-205) Hampshire: Palgrave Macmillan.

Soper, K., Ryle, M., \& Lyn, T. (2009). The Pleasures and Politics of Consuming Differently: Better Than Shopping. London: Palgrave Macmillan.

Steenhaut, S., \& Van Kenhove, P. (2006). The Mediating Role of Anticipated Guilt in Consumers' Ethical Decision-Making. Journal of Business Ethics, 69, 269-288.

Tangney, P.J., Stuewig, J., \& Mashek, J.D. (2007). Moral Emotions and Moral Behavior. The Annual Review of Psychology, 58: 345-372

Urry, J., \& Larsen, J. (2011). The Tourism Gaze, 3.0. London: Sage.

Veijola, S., \& Jokinen, E. (1994) The Body in Tourism. Theory, Culture \& Society, 11(3), 125-151. 